\title{
Value Generation in the Product Lifecycle with Digital Twins: Status Quo in Swiss Companies
}

\author{
Linard Barth \\ Zurich University of Applied \\ Sciences \\ linard.barth@zhaw.ch \\ Manuel Holler \\ Zurich University of Applied \\ Sciences \\ manuel.holler@zhaw.ch
}

\author{
Matthias Ehrat \\ Zurich University of Applied \\ Sciences \\ matthias.ehrat@zhaw.ch \\ Nikola Savic \\ Zurich University of Applied \\ Sciences \\ nikolasavic@bluewin.ch
}

\author{
Gianluca Galeno \\ Zurich University of Applied \\ Sciences \\ gianluca.galeno@zhaw.ch
}

\begin{abstract}
Value generation with digital twins along the phases of the product lifecycle affects different processes from a company's internal perspective. The present study investigated in which phases of the product lifecycle and processes swiss companies seek to generate what value contribution. The results of the survey of 103 companies show that only $47 \%$ of the companies surveyed are applying or planning to apply digital twins. The motivation primarily lies in increasing efficiency (79\%) or in building competitive advantage (63\%). These companies clearly recognize the potential of digital twins to create value in the Beginning-of-Life-phase (79\%) and in the Middle-ofLife-phase (60\%). In contrest, the use in the End-ofLife-phase (15\%) is subordinate. The companies seek to generate value with digital twins by offering qualitatively better products and services in a shorter time or with higher availability. Cost savings seem secondary and overestimated by companies before they apply digital twins.
\end{abstract}

Keywords - Digital Twin, Product Lifecycle, Value Generation

\section{Introduction}

Digitization is neither a new phenomenon nor a hype that can be expected to disappear soon. From the very beginning, the recognized central benefit of digitization has been the automation of formerly manual activities with the aim of increasing their efficiency. Saving costs and time as well as improving the quality of processes are integral components of the management of any value chain. The manufacturing industry therefore pioneered many digitization concepts and approaches what later became ubiquitous in consumer markets and eventually in everyday life. The use of cell phones and personal computers may serve as an example. Further development and progress in information and communication technologies will continuously transform traditional products into smart products and allow to offer novel smart services [1] [2] [3] [4]. In this context, the concept of digital twin is considered a key technology for value creation with smart services [5].

The origin of the digital twin concept is attributed to Michael Grieves and John Vickers of NASA, with Grieves presenting the notion in a lecture on product life-cycle management in 2003 [6]. The initial description defines a digital twin as a virtual representation of a physical product, from which it receives data and to which it provides information to optimize processes.

Since its first description a plethora of definitions of digital twins arose from authors from different application and research fields. However, it should be emphasized that many publications avoid defining explicitly the digital twin concept for themselves. They rather implicitly assume a certain set of abilities and properties, thus aggravating the forming of an accurate definition [7]. The nature of the digital twin is, for example, paraphrased as a multi-domain simulation [8], a computerized counterpart of a physical system [9], a virtual representation of what has been produced [10], a virtual substitute of real world objects [11], an integrated simulation and forecasting tool [12] or a linked collection of digital artifacts [13].

Trying to avoid the multiplicity of terms, the Industrial Internet Consortium (IIC) has proposed the following definition for digital twin [14]: "Digital representation, sufficient to meet the requirements of a set of use cases." Where a digital representation itself is defined as "Information that represents attributes and behaviors of an entity". And where an entity is defined as an "item that has recognizably distinct 
existence, such as a person, an organization, a device, a machine tool, a production line, a sub-system, or a group of such items". This definition of the ICC pursues the goal of spreading the concept of digital twins more widely and more quickly in corporate practice, in that a) the authenticity of the digital twin only has to be "sufficient" and b) not only physical products but "everything of value to the company" can be managed via a digital representation. This approach is welcome, as research on digital twins has reached a high level of maturity and has been shifting from theoretical foundations to practical applications for several years, as shown in Figure 1. The understanding of digital twins of this practice-oriented approach was taken as a basis during the development of the survey and this paper.

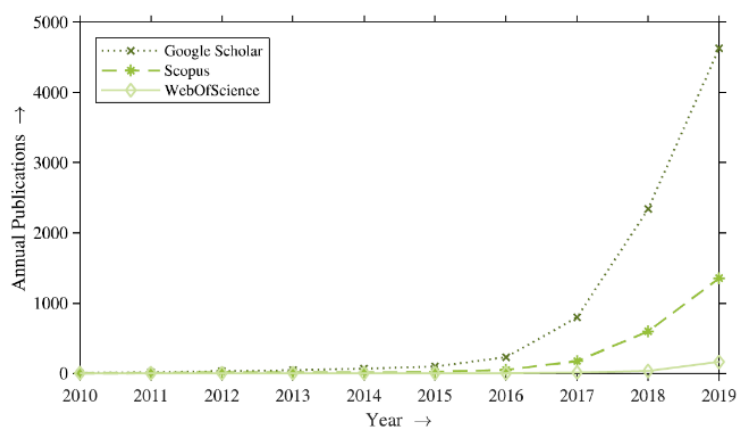

Figure 1: Number of practice-oriented publications per year carrying "Digital Twin" in their title determined using different scientific search engines [7].

The digital twin concept gains increasing attention and popularity among practitioners in Europe. For example, the German "Industrie 4.0" initiative, which specified the well-known "Reference Architecture Model Industrie 4.0" (RAMI 4.0) - in which the "Asset Administration Shell" (AAS) is closely related to digital twins from a conceptual point of view [15] adopts the concept of the digital twin to an increasing extent. It is noteworthy in this regard, that the latest user organization formed in Germany at the end of 2020 to promote RAMI 4.0 and AAS is named IDTA "Industrial digital twin Association" and not AAS Association. The aim of the IDTA association is to bring together the parallel development aspects for the industrial digital twin and to develop it as an opensource solution together with the member companies [16]. Among the 20 member companies are wellknown industry-leaders such as ABB, Bosch, Siemens, or Volkswagen, which illustrates the high relevance for practice. In May 2021, the Swiss train manufacturer Stadler Rail and Deutsche Bahn announced their intention to have fully functional digital twins of trains in operation by the end of 2021
[17]. The following two forecasts make clear that the application of digital twins has arrived in practice: Even though the digital twin concept is relatively young, the market is estimated to grow from USD 3.8 billion in 2019 to USD 35.8 billion by 2025 , at a CAGR of $37.8 \%$ [18]. And the International Data Corporation (IDC) projects that by $2022,40 \%$ of IoT platform vendors will integrate simulation platforms, systems, and capabilities to create digital twins, with $70 \%$ of manufacturers using the technology to conduct process simulations and scenario evaluations [19].

With digital twins, companies seek to generate value in both the internal dimension (internal processes regarding product lifecycle) as well as the external dimension (during the usage phase in the market) [20]. In its survey on the state of digitization in Switzerland published in March 2021, the Swiss platform initiative Industrie 2025 found that industrial companies still place a strong focus on the digitization of their internal processes [21]. In the survey, 70\% describe the automation of production and related internal processes as an "important" or "very important" strategic challenge. The recommendations for action to Swiss industry from Industrie2025 are correspondingly clear: Companies should consider all fields of action of digitization and therefore not limit themselves to optimizing the development and realization processes but should further initiate significant efforts to develop the decisive fields of servitization in the usage phase. Interestingly the survey doesn't mention any processes of relevance for a closed loop PLM [22] embracing the entire product lifecycle "from cradle to cradle" [23] and encompassing further process steps such as resale, buyback, or recycling. This is of particular interest against the background of the German Acatech, which in its considerations on the need for research and development for the successful implementation of "Industrie 4.0" explicitly refers to the need for sustainable methods for the end-of-life use options that extend the original life cycle [24]. Except for a representative study [25] that examined the feasibility of digital twins but not their value contribution, no other studies are known regarding the use of digital twins in practice in Swiss companies.

In summary, it can be stated that the concept of the digital twin is of central importance for the upcoming changes during digitalization and the comprehensive implementation of "Industrie 4.0". However, in the application-related contributions and in the academic literature, this concept is still understood in different ways and there is a lack of studies on the actual status of the implementation of the concept of the digital twin along the product lifecycle in companies. 
This study therefore aims to contribute to the understanding of the application of digital twins in practice by examining how far companies in Switzerland are in generating internal value with digital twins. It systematically analyzes which phases of the product lifecycle are already covered or are planned for implementation, which processes and what value contribution based on digital twin applications is in the foreground.

\section{Methods and Material}

The research at hand therefore focuses on the objective to examine how far companies in Switzerland are about the application of digital twins, in which phases of the product lifecycle and process steps they are applied, and which values are to be generated. To achieve this goal, a survey was conducted, which was structured along the following three guiding research questions: a) What share of companies already apply or are planning to apply digital twins to generate value in internal processes, b) in which phases of the product lifecycle and process steps do these companies apply or plan to apply digital twins and c) which values are or shall be generated within the phases of the product lifecycle?

The product lifecycle in the questionnaire was divided first into Beginning-of-Life (BoL), Middle-ofLife (MoL) and End-of-Life (EoL) [26] and secondly in the corresponding sub-processes as shown in figure 2.

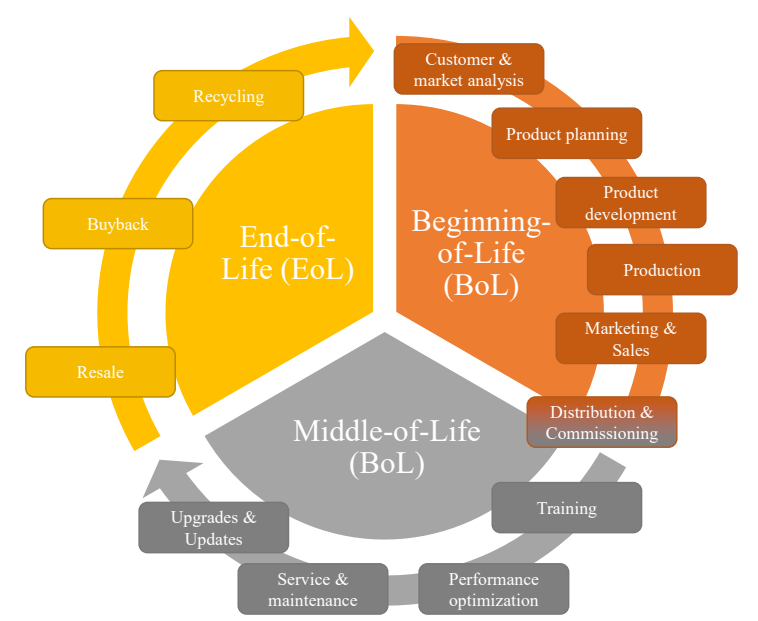

Figure 2: Closed Loop Product Lifecycle

The questionnaire was structured accordingly as seen in table 1 . In the introductory questions, it was determined whether the participant's company already applies digital twins, whether the application is planned, or whether there are currently no intentions to apply digital twin for the value creation along the product lifecycle. The three groups formed were subsequently asked different questions so that appropriate evaluations could be carried out. For example, the questions regarding value generation in the BoL phase were only presented to participants who had previously indicated that they were applying or planning to apply digital twins in this phase.

Table 1: Questionnaire structure

\begin{tabular}{clc} 
Section & \multicolumn{1}{c}{ Question topic } & Questions \\
\hline 1 & Introduction and instruction & - \\
2 & Introductory questions about digital twins & $1-2$ \\
3 & Questions for group "applying digital twins" & $3-13$ \\
4 & Questions for group "planning to apply digital twins" & $14-26$ \\
5 & Questions for group "not planning to apply digital twins" & $27-29$ \\
6 & Company details & $30-33$
\end{tabular}

The online questionnaire was distributed within relevant interest groups in different social media channels, mainly Swiss product management groups on LinkedIn, and the personal network of the researchers.

The final sample consisted of 103 fully completed questionnaires. In terms of sectors, company representatives from 13 different industries took part, with a high proportion of participants from the mechanical and plant engineering sector (27\%). Except for the aerospace sector with only one participant, the other sectors are quite evenly distributed and account for $3-10 \%$ of the total participants, with services (finance, education, tourism) and the food industry forming the second and third largest segments with approximately $10 \%$ each. Also, regarding company sizes the answers are relatively evenly distributed: $33 \%$ of the companies employ fewer than 50 people, $20 \%$ employ between 50 and 249 people, $26 \%$ employ between 250 and 2,499 people and $20 \%$ employ more than 2,500 people.

\section{Results}

This section is structured as follows: The first section presents the responses regarding the general application of digital twins to generate value, as well as the underlying motivation. The second section then presents and compares the responses of the companies that already apply or plan to apply digital twins regarding the phases of the product lifecycle and process steps. The third section presents and discusses the values the companies generate or intend to generate with digital twins in the product lifecycle phases. 


\subsection{Application and Motivation}

The following table 2 shows the share of companies stating they already apply digital twins, plan to apply digital twins or with no intentions to apply digital twins for the value creation along the product lifecycle phases.

\section{Table 2: Share of companies applying or planning} to apply DT for value generation

Q: Do you already use digital twins along the product lifecycle in your company?

\begin{tabular}{lcccccccc}
$\begin{array}{l}\text { Prior } \\
\text { knowledge }\end{array}$ & \multicolumn{2}{c}{$\begin{array}{c}\text { Yes, DT } \\
\text { applied }\end{array}$} & \multicolumn{2}{c}{$\begin{array}{c}\text { Not yet, but } \\
\text { planned. }\end{array}$} & $\begin{array}{c}\text { No, and not } \\
\text { planned. }\end{array}$ & Total \\
\hline Low & 3 & $13 \%$ & 8 & $32 \%$ & 45 & $82 \%$ & 56 \\
\hline Medium & 9 & $39 \%$ & 17 & $68 \%$ & 8 & $15 \%$ & 34 \\
\hline High & 11 & $48 \%$ & 0 & $0 \%$ & 2 & $4 \%$ & 13 \\
\hline Total & 23 & $100 \%$ & 25 & $100 \%$ & 55 & $100 \%$ & 103
\end{tabular}

Almost a quarter (23 out of 103) of the companies surveyed currently apply digital twins to generate value. Another quarter (25 out of 103) plans to apply digital twins to create value along the product lifecycle. Together these companies make up for roughly half (48 out of 103) of the companies surveyed and represent the sample for the questions regarding the application in different phases of the product lifecycle and processes. Accordingly, more than half of the companies surveyed do not apply or plan to apply digital twins in the foreseeable future.

Not surprisingly, the answers correlate with the self-declared prior knowledge regarding digital twins. Only the companies already applying digital twins exhibit a remarkable proportion of participants declaring "high prior knowledge" (48\%). Of the participants from companies that are planning to apply digital twins, "medium prior knowledge" was chosen the most (68\%). While "low prior knowledge" was stated by more than 4 out of 5 participants $(82 \%)$ from the companies that do not plan to apply digital twins. As the application of digital twins to generate value along the product lifecycle is challenging, a certain know-how level is required and therefore the positive correlation between knowledge and application maturity is evident.

Examining the answers regarding the motivation to apply digital twins in table 3 , no major difference between the companies that are already applying digital twins and those who are only planning to apply digital twins can be identified. In both groups, the possibility of increasing efficiency is the greatest motivating factor, followed by the motivation to build competitive advantage.
Table 3: Motivation of companies to apply digital twins

Q: What was the motivation for applying digital twins in your company? (Multiple selection)

\begin{tabular}{|c|c|c|c|c|c|c|c|}
\hline & 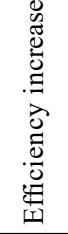 & 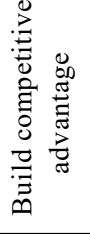 & 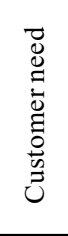 & 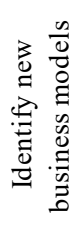 & 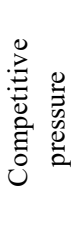 & $\frac{\bar{d}}{\overline{0}}$ & 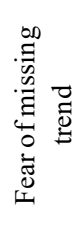 \\
\hline \multirow{2}{*}{$\begin{array}{c}\text { DT applied } \\
\quad(\mathrm{n}=23)\end{array}$} & 20 & 14 & 11 & 9 & 5 & 5 & 2 \\
\hline & $87 \%$ & $61 \%$ & $48 \%$ & $39 \%$ & $22 \%$ & $22 \%$ & $9 \%$ \\
\hline \multirow{2}{*}{$\begin{array}{l}\text { DT planned } \\
\quad(\mathrm{n}=25)\end{array}$} & 18 & 16 & 11 & 11 & 3 & 2 & 1 \\
\hline & $72 \%$ & $64 \%$ & $44 \%$ & $44 \%$ & $12 \%$ & $8 \%$ & $4 \%$ \\
\hline \multirow{2}{*}{ Total $(n=48)$} & 38 & 30 & 22 & 20 & 8 & 7 & 3 \\
\hline & $79 \%$ & $63 \%$ & $46 \%$ & $42 \%$ & $17 \%$ & $15 \%$ & $6 \%$ \\
\hline
\end{tabular}

It therefore seems that companies are expecting to increase both efficiency and effectiveness of their offerings by the application of digital twins, especially when it comes to meeting customer needs. This assumption is supported by a likewise high motivation of the companies to apply digital twins to meet customer needs and identify new business models, which follow on rank three and four. Each being a motivation to apply digital twins for a little less than half of the companies surveyed. Competitive pressure and the fear of missing out on a trend are motivating factors for a small proportion of respondents. Overall, it can be stated that the pressure from customers and competition seems to be rather low. Companies that are already applying digital twins or are planning to do so are therefore likely to be early movers and technology leaders as they focus on optimizing efficiency, building future competitive advantages, and exploring new business models.

A similar picture can be drawn when examining the responses from companies that are not planning to apply digital twins as shown in table 4. The main reasons that speak against the application of digital twins seem modifiable: Lack of know-how and unsuitable business models. The mainly technological reasons on rank three to five might also change with technological development, leading to cheaper sensors and tools needed to create digital twins. For most companies neither the management nor the willingness to pay or the willingness to share data of customers are obstacles to apply digital twins in the future. Accordingly, 37 out of $55(67 \%)$ stated that they would continue to pursue the topic of "digital twins", although there are currently no plans to apply them. 
Table 4: Reasons to not apply digital twins

Q: Which reasons speak against the use of digital twins in your company? (Multiple selection)

\begin{tabular}{ccc}
\hline & $\begin{array}{c}\text { Not planning to apply DT } \\
(\mathrm{n}=55)\end{array}$ \\
\hline No suitable business model & 27 & $49 \%$ \\
\hline Lack of know-how & 25 & $45 \%$ \\
\hline $\begin{array}{c}\text { No/low added value (cost- } \\
\text { benefit ratio) }\end{array}$ & 15 & $27 \%$ \\
\hline $\begin{array}{c}\text { Products cannot be networked } \\
\text { or equipped with sensors }\end{array}$ & 15 & $27 \%$ \\
\hline $\begin{array}{c}\text { Insufficient IT infrastructure } \\
\text { Lack of interest from } \\
\text { management }\end{array}$ & 10 & $18 \%$ \\
\hline $\begin{array}{c}\text { Too costly } \\
\text { customers }\end{array}$ & 9 & $16 \%$ \\
\hline $\begin{array}{c}\text { Lack of willingness to pay by } \\
\text { Lack of willingsness to share } \\
\text { data by customers }\end{array}$ & 7 & $16 \%$ \\
\hline Other & 5 & $9 \%$ \\
\hline
\end{tabular}

\subsection{Product lifecycle and process steps}

Regarding the application of digital twins to generate value in the product lifecycle, it can be seen in table 5, that in terms of the three life-cycle phases, digital twins are most frequently applied or planned to be applied in the BoL phase (79\%). Digital twins are also frequently applied or planned to be applied in the MoL phase $(60 \%)$, but significantly less in the EoL phase $(15 \%)$. Comparing the two groups that are already applying digital twins and those that are only planning to apply them, two differences can be noticed. First, the MoL phase was mentioned slightly

\section{Table 5: Phases of the product lifecycle}

Q: In which phases of the product lifecycle are digital twins currently used in your company? (Multiple selection)

\begin{tabular}{|c|c|c|c|}
\hline $\begin{array}{c}\text { Product } \\
\text { lifecycle } \\
\text { phase }\end{array}$ & $\begin{array}{l}\text { Beginning-of- } \\
\text { Life (BoL) }\end{array}$ & $\begin{array}{l}\text { Middle-of- } \\
\text { Life (MoL) }\end{array}$ & $\begin{array}{l}\text { End-of-Life } \\
\text { (EoL): }\end{array}$ \\
\hline \multirow{2}{*}{$\begin{array}{l}\text { Applying } \\
\text { DT }(n=23)\end{array}$} & 18 & 16 & 1 \\
\hline & $78 \%$ & $70 \%$ & $4 \%$ \\
\hline \multirow{2}{*}{$\begin{array}{l}\text { Planning to } \\
\text { apply }(n=25)\end{array}$} & 20 & 13 & 6 \\
\hline & $80 \%$ & $52 \%$ & $24 \%$ \\
\hline \multirow{2}{*}{ Total $(n=48)$} & 38 & 29 & 7 \\
\hline & $79 \%$ & $60 \%$ & $15 \%$ \\
\hline
\end{tabular}

more frequently by the companies that are already applying digital twins (70\% vs $52 \%$ ). This could be due to the fact that the companies that are not currently applying digital twins will introduce them first in the BoL phase in order to create the foundations for their application in the other phases. Secondly, despite the relatively small sample size, it can be noted that the EoL phase was mentioned more frequently by the companies that are only planning to apply digital twins ( $24 \%$ vs $4 \%)$. A closer look at the individual responses reveals that five of the six companies that indicated the intention to apply digital twins for the EoL phase selected all three phases of the product lifecycle. Hence, it might be assumed that the companies which plan to apply digital twins are planning this in a holistic manner. However, this part of the sample is too small for a reliable statement.

More insights regarding the application of digital twins in the product lifecycle can be obtained from the consideration of the individual process steps shown in table 6 . The total of 48 companies that already apply digital twins (23 out of 48 ) or plan to apply them ( 25 out of 48) selected a total of 186 process steps. This means that the companies only apply or plan to apply on average $30 \%$ (3.875 out of 13) of all queried process steps. It is further noteworthy that none of the companies surveyed reported generating or planning to generate value with digital twins in all 13 process steps of the product lifecycle. In the survey, a maximum of 9 out of the 13 queried process steps were selected. Overall, the results therefore show a very intentional approach to determining the process steps in which to apply digital twins for the value generation.

In the BoL phase, product development and production were considered relevant by $68 \%$ and $66 \%$ of the companies, respectively, and product planning by $53 \%$ of the companies. It can be assumed that since digital twins are frequently developed by product development departments, they are often applied there first and secondly in subsequent production processes. In addition, the values generated in these two process steps are comparatively easy to quantify due to the high availability of data, which makes investment decisions much easier. Market-side process steps such as customer and market analysis or marketing and sales, on the other hand, were considered significantly less important by $26 \%$ respectively $37 \%$ of the companies. Interestingly the results of the companies that already apply digital twins are higher in all process steps of the BoL phase than of the companies who plan to apply digital twins. On average companies apply digital twins in 3.33 out of $6(56 \%)$ process steps, while the companies planning to apply digital 
twins do so in 2.5 out of 6 process steps (42\%) queried in the BoL phase.

In the MoL phase, the choice is also pronounced. $79 \%$ of the companies consider applying the process step of maintenance and service to generate value with digital twins. This might be again due to the fact, that these added values are simple to quantify and commercialize, since the therefore needed data, willingness to pay by customers and contracts for service \& maintenance are often already existing. Additionally, applying digital twins for this process step likely leads to an increase of customer interaction, retention, and satisfaction. Performance optimization and upgrades or updates also play an important role with $59 \%$ and $52 \%$ respectively. Training, on the other hand, is given a less important role with only $34 \%$. The companies applying digital twins again chose more process steps in the MoL phase than those not planning their application, but not as significantly as in BoL. Service \& maintenance was even chosen relatively more frequently from the companies, that only plan to apply digital twins.

In the EoL phase, resale and recycling are considered very relevant with $71 \%$ each. However, this must be put into perspective, as only 7 out of 48 companies even consider the EoL phase to be relevant for the application of digital twins.

\subsection{Value generation}

After the results regarding the application of digital twins in the different phases of the product lifecycle and the process steps contained therein have been shown, the following section is addressed to the generated or planned value with digital twins. Table 7 lists the values assessed in the survey that can be generated with digital twins in the BoL phase in descending order of their average. In addition, the values are divided separately into companies that are already applying digital twins and those that are planning to apply them.

Both groups rated quality improvement as the value best generated with digital twins. Optimizing throughput times and the adherence to schedules is on rank two and improved product development and shorter time-to-market follow on rank three. The top three ranked values directly relate to the process steps where digital twins are applied or planned to be applied the most in the BoL phase according to the results in table 6: product development and production. Rank 4, the better understanding of customers and markets is rather interesting, as only a quarter of the companies stated in the earlier question (see table 6), that they apply or plan to apply digital twins for customer \& market analysis. This discrepancy could be explained, as that even though companies recognize the high potential of the digital twin to generate value by improving the analysis of customers and markets, they lack the ability to collect and add customer and market related data to the digital twin, so the potentially high values cannot be fully exploited. Cost reduction as a generated value of the application of digital twins is ranked on the $5^{\text {th }}$ place, due to a very high rating by the companies who plan to apply digital twins, as this value received the $2^{\text {nd }}$ highest score of all values in this group. Cost reduction also shows the highest difference between the two groups in the BoL phase. At this point, we can only speculate about the reasons for this high discrepancy. It seems reasonable to assume that the expectations of being able to reduce costs by using digital twins in the BoL phase are inflated in practice.

Table 6: Phases of the product lifecycle and process steps where digital twins are applied or planned to be applied for value generation

\begin{tabular}{|c|c|c|c|c|c|c|c|c|c|c|c|c|c|c|c|c|}
\hline \multirow[b]{3}{*}{$\begin{array}{c}\text { Process } \\
\text { steps }\end{array}$} & \multicolumn{16}{|c|}{$\begin{array}{l}\text { Q: In which process step of the product lifecycle are digital twins applie } \\
\text { (Multiple selection) }\end{array}$} \\
\hline & \multicolumn{6}{|c|}{ BoL } & \multicolumn{5}{|c|}{ MoL } & \multirow[b]{2}{*}{$\begin{array}{l}\text { Process } \\
\text { steps }\end{array}$} & \multicolumn{3}{|c|}{ EoL } & \multirow[b]{2}{*}{ 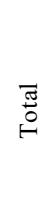 } \\
\hline & 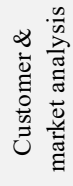 & 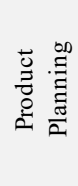 & 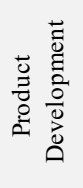 & 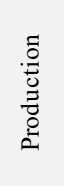 & 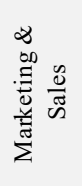 & 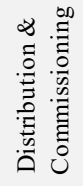 & $\begin{array}{l}\text { Process } \\
\text { steps }\end{array}$ & $\stackrel{\infty}{\Xi}$ & 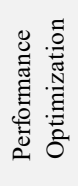 & 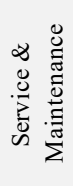 & 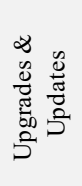 & & $\begin{array}{l}\frac{0}{\widetilde{J}} \\
\stackrel{0}{0} \\
\simeq\end{array}$ & 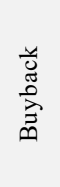 & 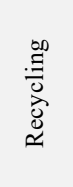 & \\
\hline \multirow{2}{*}{$\begin{array}{l}\text { DT applied } \\
\quad(\mathrm{n}=18)\end{array}$} & 5 & 11 & 15 & 13 & 7 & 9 & \multirow{2}{*}{$\begin{array}{l}\text { DT applied } \\
\quad(\mathrm{n}=16)\end{array}$} & 6 & 10 & 12 & 9 & \multirow{2}{*}{$\begin{array}{l}\text { DT applied } \\
\quad(\mathrm{n}=1)\end{array}$} & 1 & 0 & 1 & 99 \\
\hline & $28 \%$ & $61 \%$ & $83 \%$ & $72 \%$ & $39 \%$ & $50 \%$ & & $38 \%$ & $63 \%$ & $75 \%$ & $56 \%$ & & $100 \%$ & $0 \%$ & $100 \%$ & \\
\hline \multirow{2}{*}{$\begin{array}{l}\text { DT planned } \\
\qquad(\mathrm{n}=20)\end{array}$} & 5 & 9 & 11 & 12 & 7 & 6 & \multirow{2}{*}{$\begin{array}{l}\text { DT planned } \\
\quad(n=13)\end{array}$} & 4 & 7 & 11 & 6 & \multirow{2}{*}{$\begin{array}{l}\text { DT planned } \\
\quad(n=6)\end{array}$} & 4 & 1 & 4 & 87 \\
\hline & $25 \%$ & $45 \%$ & $55 \%$ & $60 \%$ & $35 \%$ & $30 \%$ & & $31 \%$ & $54 \%$ & $85 \%$ & $46 \%$ & & $67 \%$ & $17 \%$ & $67 \%$ & \\
\hline \multirow{2}{*}{ Total $(n=38)$} & 10 & 20 & 26 & 25 & 14 & 15 & \multirow{2}{*}{ Total $(n=29)$} & 10 & 17 & 23 & 15 & \multirow{2}{*}{ Total $(n=7)$} & 5 & 1 & 5 & 186 \\
\hline & $26 \%$ & $53 \%$ & $68 \%$ & $66 \%$ & $37 \%$ & $39 \%$ & & $34 \%$ & $59 \%$ & $79 \%$ & $52 \%$ & & $71 \%$ & $14 \%$ & $71 \%$ & \\
\hline
\end{tabular}




\section{Table 7: Value generated in BoL}

Q: What value do you or plan to generate by applying digital twins in the Beginning-of-Life? (rating)

\begin{tabular}{|c|c|c|c|c|}
\hline $\begin{array}{l}\text { Generated value (rated } \\
\text { from } 0=\text { "not } \\
\text { generated" to } 3=\text { "fully } \\
\text { generated") }\end{array}$ & $\begin{array}{c}\text { DT } \\
\text { applied } \\
(\mathrm{n}=18)\end{array}$ & $\begin{array}{c}\text { DT } \\
\text { planned } \\
(n=20)\end{array}$ & $\begin{array}{c}\text { Average } \\
\varnothing^{\downarrow} \\
(n=38)\end{array}$ & $\begin{array}{l}\text { Differ- } \\
\text { ence } \Delta\end{array}$ \\
\hline $\begin{array}{c}\text { Quality } \\
\text { improvement }\end{array}$ & 2.44 & 2.67 & 2.55 & -0.23 \\
\hline $\begin{array}{l}\text { Optimized throughput } \\
\text { times and adherence to } \\
\text { schedules }\end{array}$ & 2.31 & 2.37 & 2.34 & -0.06 \\
\hline $\begin{array}{c}\text { Improved product } \\
\text { development and } \\
\text { shorter time-to-market }\end{array}$ & 2.24 & 2.35 & 2.30 & -0.11 \\
\hline $\begin{array}{c}\text { Better understanding } \\
\text { of customers and } \\
\text { markets }\end{array}$ & 2.27 & 2.05 & 2.16 & 0.21 \\
\hline $\begin{array}{c}\text { Cost } \\
\text { reduction }\end{array}$ & 1.88 & 2.40 & 2.14 & -0.53 \\
\hline $\begin{array}{l}\text { Improved quotation } \\
\text { processes (e.g. } \\
\text { configuration, pricing) }\end{array}$ & 1.94 & 2.28 & 2.11 & -0.34 \\
\hline $\begin{array}{c}\text { Better capacity } \\
\text { utilization }\end{array}$ & 1.59 & 1.95 & 1.77 & -0.36 \\
\hline $\begin{array}{c}\text { Real-time remote } \\
\text { intervention in factory } \\
\text { control }\end{array}$ & 1.75 & 1.26 & 1.51 & 0.49 \\
\hline $\begin{array}{l}\text { Reduction of batch } \\
\text { sizes (mass } \\
\text { customization) }\end{array}$ & 1.56 & 1.35 & 1.46 & 0.21 \\
\hline Average & 2.00 & 2.08 & 2.04 & -0.08 \\
\hline
\end{tabular}

Improved quotation processes and better capacity utilization rank on $6^{\text {th }}$ and $7^{\text {th }}$ place respectively and were evaluated both more favorable by the group of companies which plan to apply digital twins. The opposite is true for the value of real-time remote intervention in factory control on rank 8 , which was evaluated considerably higher by the group of companies which already apply digital twins, but generally achieves a below-average rating. The significantly better rating of the group that already applies digital twins could be explained by the argument that the true added value only becomes apparent in practical use. This means that the value of real-time remote intervention in factory control is underestimated by companies planning to apply digital twins. Overall, the reduction of batch sizes received the lowest rating of all values queried in the $\mathrm{BoL}$ phase.

The results of the respective values in the MoL phase are shown in table 8 . Only quality improvement and cost reduction are identical to the values queried in the BoL phase, the other values are MoL specific. Quality improvement again was evaluated as highly relevant in the MoL phase, only process optimization / better performance was rated even higher.

\section{Table 8: Value generated in MoL}

Q: What value do you or plan to generate by applying digital twins in the Beginning-of-Life? (rating)

\begin{tabular}{|c|c|c|c|c|}
\hline $\begin{array}{l}\text { Generated value (rated } \\
\text { from } 0=\text { "not } \\
\text { generated" to } 3=" \text { "fully } \\
\text { generated") }\end{array}$ & $\begin{array}{c}\text { DT } \\
\text { applied } \\
(\mathrm{n}=16)\end{array}$ & $\begin{array}{c}\text { DT } \\
\text { planned } \\
(\mathrm{n}=13)\end{array}$ & $\begin{array}{c}\text { Average } \\
\varnothing^{\downarrow} \\
(n=29)\end{array}$ & $\begin{array}{l}\text { Differ- } \\
\text { ence } \Delta\end{array}$ \\
\hline $\begin{array}{l}\text { Process optimization / } \\
\text { better performance }\end{array}$ & 2.73 & 2.62 & 2.68 & 0.11 \\
\hline Quality improvement & 2.47 & 2.46 & 2.46 & 0.01 \\
\hline $\begin{array}{l}\text { Increased availability } \\
\text { for customers }\end{array}$ & 2.36 & 2.42 & 2.39 & -0.06 \\
\hline $\begin{array}{l}\text { Higher customer } \\
\text { satisfaction }\end{array}$ & 2.38 & 2.31 & 2.35 & 0.08 \\
\hline $\begin{array}{l}\text { Improved installation / } \\
\text { commissioning }\end{array}$ & 2.29 & 2.31 & 2.30 & -0.02 \\
\hline $\begin{array}{l}\text { Predictive Service \& } \\
\text { Maintenance }\end{array}$ & 2.00 & 2.15 & 2.08 & -0.15 \\
\hline $\begin{array}{l}\text { Improved training / } \\
\text { education for } \\
\text { customers }\end{array}$ & 2.00 & 2.08 & 2.04 & -0.08 \\
\hline $\begin{array}{c}\text { Preventive Service \& } \\
\text { Maintenance }\end{array}$ & 1.92 & 2.08 & 2.00 & -0.16 \\
\hline Cost reduction & 1.88 & 2.08 & 1.98 & -0.20 \\
\hline New business models & 1.80 & 2.08 & 1.94 & -0.28 \\
\hline $\begin{array}{l}\text { Real-time remote } \\
\text { intervention in product } \\
\text { control }\end{array}$ & 2.08 & 1.46 & 1.77 & 0.62 \\
\hline $\begin{array}{l}\text { Better up-selling and } \\
\text { cross-selling }\end{array}$ & 1.43 & 1.83 & 1.63 & -0.40 \\
\hline Average & 2.11 & 2.16 & 2.13 & -0.05 \\
\hline
\end{tabular}


The increased availability for customers and the higher customer satisfaction received the $3^{\text {rd }}$ and $4^{\text {th }}$ highest evaluations respectively, followed by improved installation and commissioning on rank 5 . Interestingly, the values of predictive and preventive service and maintenance, which have received high attention in theory and practice, were rated relatively low, slightly below average and similar to improved training and education of customers. This is particularly remarkable since $79 \%$ of the companies apply or plan to apply digital twins for service and maintenance processes, as seen in table 6 . Hence, the focus seems to be on other applications than predictive and preventive maintenance, presumably in the optimization of existing processes. With regard to the value of reducing costs, the results in the MoL phase are similar to the BoL phase, but less accentuated. Again, the companies planning to apply digital twins attest to a higher value than the companies already applying digital twins, but the difference and thus also the average of the two groups is smaller than in the BoL phase. Another noteworthy result is the low rating of generated value from digital twins for new business models, even though this is partly in line with the finding regarding the motivation to apply digital twins in tables 3 and 4 . The value of real-time remote intervention in product control in the MoL phase received the second lowest value. Here, too, the results from the BoL phase are confirmed. Once again, the value of real-time remote intervention was rated significantly higher by the companies already using digital twins. The discrepancy between the two groups is also greatest in absolute terms for this value in the MoL phase. The assumption that remote control via digital twins is generally underestimated by companies planning to apply digital twins is therefore supported. Finally, better upselling and cross-selling received the lowest rating of all values queried in the MoL phase. Which is on the one hand in line with the findings in table 6 that indicate that the market-side processes seem not in focus for the application of digital twins. On the other hand, more than half of the companies apply or plan to apply digital twins for the process steps of "upgrades \& updates" and therefore should rate the value of "upselling and cross-selling" higher.

In summary these findings again support the assumption, that the potential of value generation by intensifying the interaction with customers via digital twins is recognized but neglected and therefore not exploited in practice. This might change in the future, as the bidirectional interaction with customers via digital twins allows companies to gain information about customer- and market requirements to close the loop to product planning and development, as well as to provide customers with valuable information, e.g. for education and training, or with adequate upgrades and updates.

The queried values of the EoL phase are not presented and discussed in the paper due to the small size of the sample not allowing any significant statements.

\section{Discussion}

This paper presents and discusses the results of a non-representative survey regarding the application of digital twins for value generation in the product lifecycle and process steps in Swiss companies. In summary, it can be stated that digital twins have arrived in practice but have not yet found broad application for value generation in the product lifecycle. Currently, there seems to be little pressure from competitors or customers to apply digital twins. Companies that are already applying digital twins can therefore still be described as early adopters that seek to build up an advantage over the competition.

It further can be stated that the companies that already apply or plan to apply digital twins still focus strongly on the BoL phase and the processes therein which are directly related to the creation of products and services. However, MoL processes are also already attracting a considerable amount of attention, especially service \& maintenance and performance optimization processes. Other market- and customerrelated processes as well as EoL processes currently seem to be of lesser importance from the companies' point of view but are likely to gain in importance in the future.

With regard to the generation of value with digital twins, the focus of attention is particularly on improved quality, as well as on values which lead to time savings for the company itself or for customers. The application of digital twins is therefore not primarily aimed at cost savings, but to be able to offer qualitatively better products and services in a shorter time or with higher availability respectively.

Regarding the reduction of costs and generating value through remote control, significant differences were identified between companies that already apply digital twins or are planning to apply them. Companies that already apply digital twins estimate the value generation through cost reduction to be lower than companies that plan to apply digital twins. It can therefore be assumed that this value is overestimated by companies planning to apply digital twins. The opposite is true for value generation through remote control of products and factories, where the value seems to be significantly underestimated by companies planning to apply digital twins. 
The main limitations result from the collected questionnaires and the size of the sample. The just three-digit number of answer sheets is limited and, due to the structuring of the questionnaire with subgroups, is clearly too small in some sub-samples to make significant statements, for example with regard to the values generated in the EoL phase with digital twins. The sample can further be described as nonrepresentative, since a non-random selection of companies participated due to the distribution in social media and personal networks. Rather, the participants are presumably individuals with an above-average awareness of the topic of value generation with digital twins. Further, companies from the mechanical and plant engineering sector are particularly well represented in the sample. Significance tests, however, did not demonstrate any significant differences between the responses from different industries, but this can again also be attributed to the sample being too small. Although the survey was explicitly addressed to Swiss companies, it cannot be ruled out that participants from foreign companies took part or that the responses referred to divisions of Swiss companies that do not apply digital twins in Switzerland. Further limitations result from the nature of the questions. The given answer options regarding the phases of the product lifecycle, the process steps and the values that can potentially be generated with digital twins may also have led to a certain bias. In addition, the values generated were queried using an abstract scale and do not allow any conclusions to be drawn about the return on investment of digital twin innovation projects achieved or expected.

\section{Conclusion}

The study conducted provides a wide range of insights regarding the application of digital twins to generate value in the product lifecycle in Swiss companies, which are relevant for both practitioners and researchers in and outside of Switzerland. Further surveys with a larger and more representative sample should follow and can build on the findings of this study. For subsequent studies, it is also advisable to dive deeper into individual sub-questions in order to examines the hypotheses raised by this study.

For application-oriented research, the findings provide a multitude of avenues for further research regarding the maturity levels of the application of digital twins in practice. Of high relevance for practice seems to be, for example, i) in which order companies introduce value creation with digital twins in the product lifecycle and what the reasons are for a certain order. Based on the results presented, it can be assumed that companies start with product development and production in the BoL phase and service and maintenance in the MoL phase and address other process steps only afterwards. The exact sequence of the development steps and differences in this respect regarding different industries and products should be researched in more detail. In this context, the question also arises ii) which prerequisites and maturity levels with regard to digital twins are required in a company so that value can also be generated in market- and customer-related processes. In terms of the values generated, more in-depth research of cost reduction with digital twins would yield further practice-relevant insights, such as iii) why the value of cost reduction seems to be overestimated before digital twins are introduced. Last but not least, research should address iv) how companies can apply digital twins in EoL processes to generate value. This currently appears to be a neglected area of the product lifecycle in practice, but it is a socially highly relevant research area, especially regarding sustainability topics such as circular economies and reduction of resource consumption.

For practitioners the systematic analysis of value generation with digital twins in the product lifecycle and the process steps allows to i) gain an overview of the competitive situation, ii) classify their own status quo, and iii) plan further innovation projects with regard to the holistic application of digital twins over the entire product lifecycle.

\section{References}

[1] H. Dawid, R. Decker, T. Hermann, H. Jahnke, W. Klat, R. König and C. Stummer, "Management science in the era of smart consumer products: challenges and research perspectives.," Central European Journal of Operations Research, pp. 203-230, 2016.

[2] M. Porter and J. Heppelmann, "How Smart, Connected Products Are Transforming Competition," Harvard Business Review, vol. 92, no. 11, pp. 64-86, 2014.

[3] M. Porter and J. Heppelmann, "How Smart, Connected Products Are Transforming Competition," Harvard Business Review, vol. 93, no. 10, pp. 96-114, 2015.

[4] N. V. Wuenderlich, K. Heinonen, A. L. Ostrom, L. Patricio, R. Sousa, C. Voss and J. G. A. M. Lemmink, "“Futurizing" smart service: implications for service researchers and managers.," Journal of Services Marketing, vol. 29, no. 6/7, pp. 442-447, 2015.

[5] C. Barbieri, S. West, M. Rapaccini and J. Meierhofer, "Are practitioners and literature aligned about digital twin?," in 26th EurOma 
Conference Operations Adding Value to Society, 2019.

[6] M. Grieves, "Digital twin: Manufacturing Excellence through Virtual Factory Replication," Grieves LLC, 2003.

[7] M. Sjarov, T. Lechler, J. Fuchs, M. Brossog, A. Selmaier, F. Faltus, T. Donhauser and J. Franke, "The Digital Twin Concept in Industry - A Review and Systematization," in 25th IEEE Internatioal Conference on Emerging Technologies and Factory Automation (EFTA), 2020.

[8] F. Jaensch, A. Csiszar, C. Scheifele and A. Verl, "Digital Twins of Manufacturing Systems as a Base for Machine Learning," in 25th International Conference on Mechatronics and Machine Vision in Practice (M2VIP), Stuttgart, 2018.

[9] W. Kritzinger, M. Karner, G. Traar, J. Henjes and W. Sihn, "Digital Twin in manufacturing: A categorical literature review and classification," IFAC-PapersOnLine, vol. 51, no. 11, pp. 10161022, 2018.

[10] M. W. Grieves, Digital Twin: Manufacturing Excellence through Virtual Factory Replication, 2015.

[11] M. Schluse, M. Priggemeyer, L. Atorf and J. Rossmann, "Experimentable Digital Twins Streamlining Simulation-Based Systems Engineering for Industry 4.0," IEEE Trans. Ind. Inf., vol. 14, no. 4, pp. 1722-1731, 2018.

[12] E. Negri, L. Fumagalli and M. Macchi, "A Review of the Roles of Digital Twin in CPS-based Production Systems," Procedia Manufacturing, vol. 11, pp. 939-948, 2017.

[13] S. Boschert and R. Rosen, "Next Generation Digital Twin," Tools and methods of competitive engineering: Proceedings of the Twelfth International Symposium on Tools and Methods of Competitive Engineering -TMCE, pp. 209-218, 2018.

[14] B. Boss, S. Malakuti, S.-W. Lin, T. Uslaender, E. Clauer, M. Hoffmeister and L. Stojanovic, "Digital Twin and Asset Administration Shell Concepts and Application in the Industrial Internet and Industrie 4.0," An Industrial Internet Consortium and Plattform Industrie 4.0 Joint Whitepaper, 2020.

[15] Deutsches Institut für Normung, Reference Architecture Model Industrie 4.0 (RAMI 4.0), DIN SPEC 91345.

[16] C. Mosch and M. Billmann, "VDMA - User Organization "Industrial Digital Twin Association" founded," 24 September 2020. [Online]. Available: https://itrpv.vdma.org/viewer//v2article/render/52443301. [Accessed 8 June 2021].

[17] V. Richert, "Inside-IT," 19 May 2021. [Online]. Available: https://www.inside-it.ch/de/post/stadler- entwickelt-den-ersten-digitalen-twin-eines-zuges20210519. [Accessed 08 June 2021].

[18] A. Rais, "Growth of the digital twin market," 02 August 2019. [Online]. Available: https:/www.maschinenmarkt.international/growthof-the-digital-twin-market-a-851571/ . [Accessed 08 June 2021].

[19] C. MacGillivray, S. Crook, M. Fleming, J. Hojlo, A. Nadkarni, A. Pinder, H. Ujhazy, R. Westervelt and M. Muñoz Méndez-Villamil, "IDC FutureScape: Worldwide IoT 2019 Predictions," IDC, USA, 2018.

[20] L. Barth, M. Ehrat, R. Fuchs and J. Haarmann, "Systematization of Digital Twins: Ontology and Conceptual Framework," in In 3rd International Conference on Information Science and Systems (ICISS 2020), Cambridge, 2020.

[21] P. Hauri and B. Ricken, "Umfrage Digitalstrategie Ergebnisse," Industrie2025, Zürich, 2021.

[22] D. Kiritsis, "Closed-loop PLM for intelligent products in the era of the Internet of things," Computer-Aided Design, pp. 479 - 501, 2011.

[23] M. Holler, F. Uebernickel and W. Brenner, "Digital Twin Concepts in Manufacturing Industries - A Literature Review and Avenues for Further Research," in 18th International Conference on Industrial Engineering (IJIE), Seoul (South Korea), 2016.

[24] Acatech - Deutsche Akademie der Technikwissenschaften, "Themenfelder Industrie 4.0 - Forschungs- und Entwicklungsbedarfe zur erfolgreichen Umsetzung von Industrie 4.0," Forschungsbeirat der Plattform Industrie 4.0, München, 2019.

[25] F. Hannich, M. Hüttermann, R. Fuchs, A. Suvada, D. L. Kübler, L. Barth, R. Heierli, A. Rozumowski and T. Kiarostami, "Swiss Marketing Leadership Studie 2018: Geschwindigkeit vs. Beständigkeit," ZHAW Zürcher Hochschule für Angewandte Wissenschaften, Winterthur, 2018.

[26] J. Stark, Product Lifecycle Management: 21st Century Paradigm for Product Realisation, 2nd ed., London: Springer, 2011. 